Cristina I. Pravia, MD

Assistant Professor, Department of Internal Medicine

University of Miami Miller School of Medicine,

Miami, FL
Merline Benny, MD

Assistant Professor, Department of Pediatrics, University of Miami Miller School of Medicine, Miami, FL

\title{
Long-term consequences of prematurity
}

\section{ABSTRACT}

Due to a shortened period of in utero organ development, premature infants are at higher risk of chronic respiratory, cardiac, renal, and endocrine system disorders later in life. With more premature babies being born and more of them surviving, internists and primary care practitioners should be aware of their patient's birth history and of the potential long-term effects of prematurity. Such understanding can lead to early detection of disease and targeted lifestyle modifications.

\section{KEY POINTS}

About $10 \%$ of live births are premature, and rates are increasing.

Survivors of premature birth may have later adverse health effects related to organs failing to achieve optimal development.

Increased risk of cardiovascular, metabolic, and kidney diseases suggest that risk factors should be monitored and patients counseled on maintaining a healthy lifestyle.

Pulmonary vulnerabilities warrant asthma control as needed, keeping current on influenza and Pneumococcus vaccinations, and avoiding smoking.

The authors report no relevant financial relationships which, in the context of their contributions, could be perceived as a potential conflict of interest.

doi:10.3949/ccjm.87a.19108 edical attention to premature babies 1 usually focuses exclusively on immediate survival and monitoring of problems in early childhood. As advancing technology has allowed more early neonates to survive with apparently good outcomes, long-term health consequences of prematurity are less often considered, although evidence indicates that they can be significant.

This article reviews lifelong pulmonary, renal, cardiac, neurologic, and endocrine vulnerabilities associated with prematurity and suggests recommendations for routine management of adults who were born premature.

\section{PREMATURITY:}

\section{DEFINITIONS AND EPIDEMIOLOGY}

Prematurity is defined by the World Health Organization $^{1}$ as birth occurring before 37 weeks of gestation, with the following categories:

- Extremely preterm $(<28$ weeks $)$

- Very preterm (28-32 weeks)

- Moderate to late preterm (32-36 weeks).

Prematurity is the main cause of neonatal death globally, accounting for $16 \%$ of deaths of children under age 5 in 2014. That year, the worldwide preterm birth rate was $10.6 \%$, or nearly 15 million infants. ${ }^{1}$

US figures are as follows:

- $10.0 \%$ of live births occurred before 37 weeks of gestation (2018 data) ${ }^{2}$

- Preterm birth rates $(<37$ weeks of gestation) were $13.6 \%$ in Black women, $9.5 \%$ in Hispanic women, and 9.1\% in non-Hispanic White women (2016 data) $)^{3}$

- $2.8 \%$ of live births occurred before 34 weeks of gestation (2016 data) ${ }^{3}$

- $0.7 \%$ of births occurred before 28 weeks of gestation (2012 data). ${ }^{4}$ 
A 2013 meta-analysis found that Black women had twice the rate of premature births compared with White women after adjusting for potential confounders such as socioeconomic status, maternal age, and parity. ${ }^{5}$

Rates of prematurity in the United States have been increasing as more women become pregnant at older ages and as assisted reproductive technologies more often result in multiple gestations and higher-risk pregnancies.

\section{WITH ADVANCES, IMPROVED SHORT-TERM SURVIVAL}

Survival rates for premature infants dramatically improved in the 1980s and 1990s thanks to adoption of surfactant, antenatal corticosteroids, and noninvasive ventilation. ${ }^{6}$ In general, better survival has been accompanied by better outcomes, ie, avoiding major impairments. ${ }^{7}$

Morbidity and mortality rates increase with shorter gestational age, with girls tending to fare better than boys. ${ }^{8}$ In 2012 , rates of survival to hospital discharge in the extremely premature ranged from $9 \%$ at 22 weeks to $94 \%$ at 28 weeks for those treated at an academic medical center that had expertise in high-risk obstetrics and specialized neonatal intensive care units. ${ }^{4}$

\section{is the main}

cause of neonatal death globally

\section{HIDDEN LONG-TERM HEALTH EFFECTS}

Despite improvements in short-term survival, early antenatal and postnatal exposures may have lifelong health consequences, a concept known as "developmental programming" or the Barker hypothesis., ${ }^{9,10}$ As the third trimester of pregnancy ( $>28$ weeks) is a period of rapid organ growth and maturation, premature infants are born before major organ development is complete. Survivors of premature birth may have later adverse health effects related to organs failing to achieve optimal development or undergoing more rapid decline. ${ }^{10}$

In addition to specific organ vulnerabilities, oxidative stress of the altered environment at birth causes telomere length shortening and DNA methylation, leading to epigenetic modifications that may appear later in life. ${ }^{11}$ The hypothalamic-pituitary-adrenal axis is overly stimulated as these babies face early adaptation to the outside world, possibly leading to more rapid "wear-and-tear."12

\section{LATER SURVIVAL IMPACTED}

As the first generation of survivors of extremely preterm birth are now entering middle age, primary care providers should be aware of the disease burden they may carry. Unfortunately, research into the long-term consequences of prematurity is limited; many of the population-based studies are based on Scandinavian birth and morbidity rates before the era of antenatal steroids and continuous positive airway therapy.

A 2011 Swedish national cohort study of people born between 1973 and 1979 who survived to 1 year found that preterm birth was associated with increased mortality in early childhood (ages 1-5 years) and young adulthood (ages 18-36), even in those born late preterm (34 to 36 weeks)..$^{13}$ In a follow-up study extending the population to those born up to 1997, the prevalence of survival without any major comorbidities at ages 18 to 43 years was $55 \%$ of those born preterm $(22 \%$ of those born extremely preterm, $49 \%$ of those born very preterm, and $58 \%$ of those born late preterm) vs $63 \%$ of those born full-term. ${ }^{14}$

Effects of prematurity on individual organ systems are summarized in Table 1 and described in more detail below.

\section{PULMONARY SYSTEM}

Impaired vascular and alveolar development Multiplication of lung capillaries and development of the air-blood barrier occur before the 26th week of gestation, but most alveolar development occurs in the last trimester. ${ }^{15}$ Preterm birth is associated with alveolar simplification and impaired pulmonary vascular development and is a risk factor for neonatal and childhood pulmonary vascular disease. Strategies to reduce lung injury, including noninvasive ventilation, improve long-term outcomes. ${ }^{4}$ However, aberrant lung vascularization as a consequence of premature birth adversely affects the lung's future vascular development. It may also stress the myocardium, with right ventricular dysfunction causing pulmonary artery hypertension later in life, especially with exposure to other factors that 


\section{TABLE 1}

\section{Effects of prematurity on organ systems, and management recommendations}

\begin{tabular}{|c|c|c|}
\hline Organ system & Increased risks & Management \\
\hline \multirow[t]{4}{*}{ Pulmonary } & \multirow{4}{*}{$\begin{array}{l}\text { Obstructive disease, } \\
\text { pulmonary hypertension }\end{array}$} & Evaluate previous asthma diagnosis \\
\hline & & Consider baseline pulmonary function testing \\
\hline & & Avoid smoking, maintain healthy weight, promote exercise \\
\hline & & Keep current on influenza and Pneumococcus vaccinations \\
\hline \multirow[t]{5}{*}{ Renal } & \multirow[t]{5}{*}{ Chronic kidney disease } & Monitor blood pressure regularly \\
\hline & & Avoid nephrotoxins \\
\hline & & $\begin{array}{l}\text { Control blood pressure (consider an angiotensin-converting } \\
\text { enzyme inhibitor if a hypertension medication is needed) }\end{array}$ \\
\hline & & Limit salt intake \\
\hline & & $\begin{array}{l}\text { Consider periodic urine microalbumin screening, renal } \\
\text { ultrasonography }\end{array}$ \\
\hline \multirow[t]{3}{*}{ Cardiovascular } & \multirow{3}{*}{$\begin{array}{l}\text { Hypertension, ischemic heart disease, } \\
\text { congestive heart failure, peripheral } \\
\text { vascular disease }\end{array}$} & Monitor blood pressure regularly \\
\hline & & $\begin{array}{l}\text { Avoid smoking, maintain healthy weight, promote } \\
\text { exercise }\end{array}$ \\
\hline & & $\begin{array}{l}\text { Consider baseline echocardiogram with appropriate car- } \\
\text { diovascular risk assessment }\end{array}$ \\
\hline \multirow[t]{5}{*}{ Endocrine } & \multirow{5}{*}{$\begin{array}{l}\text { Diabetes, metabolic syndrome, obesity, } \\
\text { osteoporosis }\end{array}$} & Monitor blood glucose, body mass composition, lipids \\
\hline & & Maintain healthy body weight and abdominal girth \\
\hline & & Ensure appropriate calcium and vitamin D supplementation \\
\hline & & Promote weight-bearing exercise \\
\hline & & $\begin{array}{l}\text { Limit medications associated with causing metabolic } \\
\text { abnormalities, dyslipidemia, worsening bone density }\end{array}$ \\
\hline
\end{tabular}

\section{Central nervous system \\ Autism, mood disorders, intellectual disabilities}

Be alert to need for early evaluation and support further impair heart function. ${ }^{16}$

Premature infants who have pulmonary vascular disease in the first week of life are more likely to develop bronchopulmonary dysplasia and pulmonary hypertension in the postpartum period. ${ }^{17}$ A Swedish populationbased study found that survivors of preterm birth into childhood and young adulthood had a higher risk of pulmonary hypertension, even after adjusting for congenital heart defects and pulmonary diseases. ${ }^{18}$

Preterm birth, irrespective of whether ba- bies require neonatal intensive care, is associated with more respiratory symptoms, partially reversible airflow obstruction, and abnormal thoracic imaging in childhood and young adulthood compared with those born at term. Premature infants have decreased alveolar volume and greater than normal age-related decline in lung function during life. Failing to reach optimal peak lung function in early adulthood results in crossing the threshold for respiratory symptoms early even if the rate of lung function decline is normal. ${ }^{15,19}$ 
Increased asthma risk, poorer lung function

Prematurely born individuals have a 4-fold higher incidence of asthma, but it is important to differentiate between true asthma (ie, with airway inflammation and responsiveness to bronchodilators) and milder forms of bronchopulmonary dysplasia found in extremely low-birth-weight infants born in this century. ${ }^{15,20}$ Recently born premature babies have fewer but larger alveoli, with less surface area for gas exchange; they do not have ventilatorassociated barotrauma as did the earlier generations of premature babies. Most infants born at 24 weeks of gestation suffer some degree of bronchopulmonary dysplasia, but this incidence significantly decreases to less than $40 \%$ in those born after 28 weeks. ${ }^{6,18}$

Children born preterm have a higher risk of wheezing disorders ${ }^{21}$ including early and persistent wheezing ${ }^{22}$ compared with children born at term. Kotecha et $\mathrm{a}^{23}$ found a deficit of $7.2 \%$ in predicted forced expiratory volume in the first second of expiration $\left(\mathrm{FEV}_{1}\right)$ for preterm-born children without bronchopulmonary dysplasia compared with children born at term. Even late-preterm infants (33-36 weeks of gestation) exhibit respiratory abnormalities, including increased residual volume, lower respiratory compliance, and decreased expiratory flow ratio. ${ }^{24}$ Preterm birth is associated with poorer lung function and airflow impairment in adult life, with the strongest association among those born the most immature, independent of underlying pregnancy disorders or risk factors (eg, maternal smoking in pregnancy or socioeconomic status). ${ }^{25}$

\section{RENAL SYSTEM}

\section{Nephrogenesis interrupted}

Nephrogenesis continues through 34 to 36 weeks of gestation, with more than half of nephrons formed in the third trimester. ${ }^{10,26}$ Preterm babies have fewer nephrons and more abnormal glomeruli; as a result, the nephrons they do have must work harder to compensate.

Adults who were born prematurely are at higher risk of focal segmental glomerulosclerosis. $^{27,28}$ Their macrovasculature is anatomically different, with normal elastin replaced by less flexible collagen, resulting in blood vessel stiffening and a higher risk of hyper- tension. $^{13,29}$ In addition, premature infants tend to have endothelial damage, leading to higher vascular resistance, increased glomerular capillary pressure, sodium retention, and fewer glomeruli at baseline. ${ }^{13,29}$ A potentially confounding factor is exposure to nephrotoxic medications while in neonatal intensive care.

\section{Higher prevalence of kidney disease}

In a Swedish study ${ }^{13}$ with 40-year follow-up, adults born premature ( $<37$ weeks) had twice the risk of chronic kidney disease compared with term controls. Those born early term (37-38 weeks) had a 1.3-fold higher risk, and those born extremely premature $(<28$ weeks) had a 3 -fold risk, with risk being especially high in women. Despite subclinical kidney dysfunction and even $25 \%$ to $50 \%$ loss in glomerular filtration rate, tubular secretion of creatinine can maintain plasma creatinine in the normal range. ${ }^{28,29}$

A review of cardiorenal syndrome in preterm infants indicated that adults born preterm enter midlife with subclinical early chronic kidney disease (stage 2-3), and even patients with milder disease (stage 1-2) have a 25- to 100-fold higher risk of cardiovascular events. ${ }^{29}$

\section{Monitoring may be useful}

No medical society guidelines cover screening in adults who were born prematurely, although some experts suggest checking cystatin and urine microalbumin and performing renal ultrasonography. ${ }^{28,29}$ Although cystatin is more sensitive than creatinine for diagnosing abnormalities in kidney function, these tests can be expensive, and no prospective studies exist to show their validity in detecting early disease. In addition, urine microalbumin can be seen in benign situations.

\section{CARDIOVASCULAR SYSTEM}

\section{Cardiac and vascular insults}

Premature infants are exposed to hostile intrauterine and extrauterine conditions that can adversely affect the heart and vascular tree. Evidence from animal models and small studies of preterm infants shows that preterm birth interferes with normal cardiac development with potential consequences into childhood and adulthood. ${ }^{30-32}$ 
Vascular abnormalities may be evident by adolescence or early adult life, including an elevated pulse-wave velocity, increased carotid intima-media thickness, ${ }^{33}$ aortic narrowing and stiffness, and impaired microvascular function. Increased left ventricular mass with increased wall thickness and reduced luminal diameter has been reported in young adults who were born preterm. ${ }^{34}$ The heart of a preterm infant develops under different conditions in the neonatal period than it would have encountered in utero and experiences higher pressure and volume loads.

Studies have found indicators of cardiac and vascular impairments:

Cardiac dysfunction. Cardiac imaging studies in those born preterm show biventricular hypertrophy beginning in early postnatal development, and right ventricular dysfunction and reduced ejection fraction in early adulthood. ${ }^{35}$

Otherwise healthy adults born preterm demonstrate a blunted cardiac response to exercise, suggesting early cardiac dysfunction. ${ }^{16}$ Huckstep et $\mathrm{a}^{36}$ found impaired left ventricular response to physiologic stress in pretermborn young adults. The differences in cardiovascular response to exercise of normotensive young adults born preterm compared to termborn controls were striking; ejection fraction at $60 \%$ exercise capacity was $6.7 \%$ lower in the preterm group, which further declined to a $7.3 \%$ difference at $80 \%$ exercise capacity.

Hypertension. Prematurity confers a higher risk of developing hypertension. Toddlers born extremely preterm tend to have systolic blood pressure above the 90th percentile. ${ }^{27}$ In young adults born preterm, the estimated difference in office-measured systolic pressure was $3.8 \mathrm{~mm} \mathrm{Hg}$ higher than in term-born controls. ${ }^{37}$ These differences appear small but are significant, given that at the population level, a $2 \mathrm{~mm} \mathrm{Hg}$ reduction in diastolic pressure is estimated to result in a $6 \%$ reduction in the risk of coronary heart disease and a $15 \%$ reduction in risk of cerebrovascular events. ${ }^{38}$

Adolescents born preterm exhibit an imbalance in the circulatory renin-angiotensin system compared with term-born peers. ${ }^{39}$ In a case series of 6 infants (born at 23-29 weeks of gestation) with hypertension associated with severe chronic lung injury, captopril, an angiotensin-converting enzyme inhibitor, improved respiratory and cardiac indices 5 to 7 weeks after birth. ${ }^{40}$

Ischemic heart disease. A populationbased cohort study found that adults ages 30 to 43 who were born preterm (gestational age < 37 weeks) have a $53 \%$ increased relative risk of ischemic heart disease compared with a fullterm birth cohort, and those born early term (37 to 38 weeks) have a 19\% increased risk. ${ }^{41}$

Heart failure. Large epidemiologic studies in children and young adults have found that preterm birth is associated with an increased risk of heart failure. Individuals born extremely preterm ( $<28$ weeks) had a 17 -fold increased risk of heart failure compared with those born at term ( $>37$ weeks), and very preterm infants (28-31 weeks) had a more than 3 -fold risk increase. ${ }^{42}$

\section{CENTRAL NERVOUS SYSTEM}

The third trimester of pregnancy brings rapid brain development with axonal proliferation, myelination, and increased volume of gray and white matter. ${ }^{6,43}$ Very preterm infants (< 32 weeks of gestation) have a smaller hippocampus and frontotemporal regions than term infants. $^{36,44}$

During infancy, babies born premature have a higher risk of cerebral palsy, cognitive disability, and seizure disorder. The subsequent hypoxia and periventricular leukomalacia alter the formation of the prefrontal cortex and its neural network, possibly leading to behavioral symptoms.

Several neurologic conditions have links to prematurity:

Autism. Children born premature have higher rates of autism spectrum disorder: the prevalence in the United States is $1.5 \%$ overall but is $7.1 \%$ in infants born at 23 to 27 weeks of gestation. ${ }^{43}$ Differences in the disorder have also been detected. Chen et $\mathrm{al}^{45}$ found that children with autism spectrum disorder born prematurely had better peer relationships but worse nonverbal behaviors than term children with the disorder.

Mood disorders. Premature-born children tend to develop anxiety, depression, attention deficit-hyperactivity disorder, and sleep disorders, which may be diagnosed at an early
The third trimester of pregnancy is a period of rapid organ growth and maturation 
age and may persist into adulthood..$^{10,43,46}$ Systematic reviews of mental health outcomes indicate that long-term risks of depression and anxiety in preterm and low-birth weight babies are 4 times higher than in those born fullterm, ${ }^{10}$ with even babies born between 36 and 38 weeks having a higher risk of developing inattention and hyperactivity.

Intellectual disability. Children born very preterm have cognitive IQ scores 12 points lower than term babies. ${ }^{20}$ Lifelong neurodevelopmental complications are inversely correlated with gestational age at birth; in an Australian study, disability-free survival (disability defined as intellectual disability, autism, or cerebral palsy) was $42.4 \%$ for those born at 24 weeks, $78.3 \%$ for those born at 28 weeks, and $97.2 \%$ for those born full-term. Birth weight, Apgar score, socioeconomic background, and maternal ethnicity were prognostic indicators. ${ }^{47}$

\section{ENDOCRINE SYSTEM}

Disorders reflecting disruption of the endocrine system are also likelier to be found in adults who were born premature:

Diabetes. Premature infants have a higher risk of eventually developing type 1 and type 2 diabetes and insulin resistance. ${ }^{44,48,49}$ By age 18 to 43 , the risk for having type 1 diabetes was 1.2 times higher, and for type 2 diabetes 1.5 times higher, than in adults born full-term..$^{50}$ Possible mechanisms include abnormal fat deposition, decreased beta cell formation (which typically occurs in the third trimester), and an altered T-cell response, leading to the autoimmune etiology of type 1 diabetes..$^{50}$

Obesity. Fetal fat distribution, which typically begins in the second trimester of pregnancy with deposition in the head and neck area, followed by the trunk and upper and lower extremities, is radically altered. Babies born before the third trimester, a time when subcutaneous fat is rapidly deposited, tend to be leaner and have lower fat stores. ${ }^{48}$ In the first months of life, premature infants are typically placed on high-calorie diets to try to "catch up," thus causing an adiposity rebound effect.

Studies show that fat deposited too quickly the first year of life predicts future adult obe- sity. ${ }^{22}$ Fat distribution is altered in preterm babies mostly with deposits in visceral fat rather than subcutaneous fat, as seen in healthy term neonates. ${ }^{51}$ Breukhoven et $\mathrm{al}^{52}$ found that fat mass, truncal fat, and limb fat mass were higher in young adults who were born premature. Visceral fat accumulation is highly inflammatory and excess fatty acid efflux damages healthy tissue, especially in the liver and pancreas of those born with extremely low birth weight. ${ }^{48}$ Breastfeeding can help reduce the risk of obesity in low birth-weight babies.

Metabolic syndrome. Adults born preterm were 2.5 to 4 times more likely than those born full-term to meet criteria for metabolic syndrome. This held true not just for very premature infants but also for those born late preterm. ${ }^{53,54}$ Evidence on effects of prematurity on lipid levels is mixed: some studies show lower levels of low-density lipoprotein levels in adults born preterm and others higher levels. 44,54

Osteoporosis. Conflicting data surround the risk of osteoporosis in preterm-born adults. Placental transfer of calcium, magnesium, and phosphorus tends to occur in the last trimester. ${ }^{55}$ Once born, premature neonates have restricted spontaneous movement and hence, less mechanical stimulation of bone. ${ }^{56} \mathrm{Un}$ fortified breast milk and parenteral nutrition do not include enough mineral content for appropriate bone formation. Bone mass is reduced in children born premature, especially those who had a low birth weight $(<1,500 \mathrm{~g})$. This may correlate with higher fracture risk and osteoporosis in adulthood. ${ }^{55}$

\section{BIRTH HISTORY SHOULD BE PART OF THE MEDICAL RECORD}

Considering that prematurity is common and evidence for long-term health sequelae is strong, birth history should become a routine part of the patient medical record. It should include birth weight, gestational age, length of stay in neonatal intensive care, maternal smoking history, and perinatal complications (eg, the need for mechanical ventilation). ${ }^{57}$ Unfortunately, such questions are only rarely asked in an adult primary or specialty care clinic. Table 2 provides questions to ask adults about prematurity. 
A British Thoracic Society survey ${ }^{58}$ found that few adult respiratory physicians routinely consider early-life factors during patient assessment. Even when asked, acquiring such information can be a challenge; unless patients are accompanied by parents, they are unlikely to know some of these details. Studies have found that maternal recall of children's birth history provides accurate information..$^{59,60} \mathrm{~Pa}$ tients themselves usually know at least if they were born very premature, if from no other source than family discussion.

A more systematic method for recording neonatal data in adult patient records would be preferable; ICD-10 codes and linked electronic datasets in the medical record may be used to clarify and maintain this information through the continuum of pediatric to adult care. As pediatricians manage the early complications related to prematurity, they should play a role in keeping a patient's detailed medical history. Diagnoses acquired in childhood, such as asthma, should always be reconsidered in adulthood.

\section{PROMOTE A HEALTHY LIFESTYLE}

Birth history is nonmodifiable, but multiple other risk factors for future disease can be changed. Diet and exercise habits are especially important to review in patients who were born premature. Several studies have indicated that premature-born adults may not have well-rounded diets and may limit exercise, increasing risk of osteoporosis and cardiometabolic disease. ${ }^{61}$ A Finnish study found that premature-born young women had a less nutritious diet than women born full-term or men born either premature or full-term. ${ }^{62}$ Another study found that young adults who were born very low-birth weight had lower consumption of fruits, vegetables, and milk products. ${ }^{63} \mathrm{~A}$ study evaluating physical fitness found that young adults born prematurely demonstrated lower muscular fitness than controls. $^{64}$

Early focus on lifestyle modifications is key. Patients born prematurely should be educated about cardiovascular exercise, strength training, tobacco avoidance, good nutrition, and age-based immunizations. Primary care providers should encourage healthy habits at a
TABLE 2

\section{Questions for acquiring a detailed history for premature-born adults}

Were you born premature? If yes, do you know why?

What was your gestational age?

How much did you weigh at birth?

Were you on mechanical ventilation? If yes, for how long?

Did you have any surgeries during the neonatal period?

How long did you stay in the neonatal intensive care unit?

What was the nature and extent of any chronic disabilities after discharge from neonatal intensive care?

Did you have any other complications?

Do you have a history of long-term medication use?

young age to combat the future risk of high blood pressure, metabolic syndrome, impaired glucose regulation, reduced pulmonary function, and poorer bone health, and they should help patients understand the importance of normal blood pressure, body mass index, blood glucose levels, and cholesterol levels.

\section{WOULD SPECIAL SCREENING BE USEFUL?}

There are currently no guidelines regarding care of adults who were born premature or low birth weight. Suggestions have been made to screen using echocardiography, computed tomography calcium score testing, incentive spirometry, renal ultrasonography, and specialized blood work to gauge disease risk. However, providers would be faced with making clinical decisions that may not be evidence-based. More population-based research is needed, especially in children and adults born this century, as their needs have changed compared with those born before the 1990s.

\section{PREVENTING FUTURE PREMATURITY}

As fertility treatments become ever more successful, multiple births, births to older mothers, and prematurity are an ongoing public health issue. Prematurity may even be considered a chronic and multigenerational condition: small studies have found that adult women who were born preterm have a higher risk of having pre- 
mature births, independent of hypertension, diabetes, and abnormal fat distribution. ${ }^{51,65}$ Preventing prematurity is important; newer practice guidelines have led to a decrease of elective labor inductions before the 39th week of gestation in uncomplicated pregnancies. ${ }^{66}$

\section{REFERENCES}

1. Chawanpaiboon S, Vogel JP, Moller AB, et al. Global, regional, and national estimates of levels of preterm birth in 2014: a systematic review and modelling analysis. Lancet Glob Health 2019; 7(1):e37e46. doi:10.1016/S2214-109X(18)30451-0

2. Martin JA, Hamilton BE, Osterman MJK. Births in the United States, 2018. NCHS Data Brief 2019; (346):1-8. https://www.cdc.gov/nchs/ products/databriefs/db346.htm. Accessed November 16, 2020.

3. Martin JA, Osterman MJK. Describing the increase in preterm births in the United States, 2014-2016. NCHS Data Brief 2018; (312):1-8. https://www.cdc.gov/nchs/data/databriefs/db312.pdf. Accessed November 16, 2020

4. Stoll BJ, Hansen NI, Bell EF, et al. Trends in care practices, morbidity, and mortality of extremely preterm neonates, 1993-2012. JAMA 2015; 314(10):1039-1051. doi:10.1001/jama.2015.10244

5. Schaaf JM, Liem SM, Mol BW, Abu-Hanna A, Ravelli AC. Ethnic and racial disparities in the risk of preterm birth: a systematic review and meta-analysis. Am J Perinatol 2013; 30(6):433-450. doi:10.1055/s-0032-1326988

6. Glass HC, Costarino AT, Stayer SA, Brett CM, Cladis F, Davis PJ. Outcomes for extremely premature infants. Anesth Analg 2015; 120(6):1337-1351. doi:10.1213/ANE.0000000000000705

7. Serenius F, Ewald U, Farooqi A, et al. Neurodevelopmental outcomes among extremely preterm infants 6.5 years after active perinatal care in Sweden. JAMA Pediatr 2016; 170(10):954-963. doi:10.1001/jamapediatrics.2016.1210

8. Zisk JL, Genen LH, Kirkby S, Webb D, Greenspan J, Dysart K. Do premature female infants really do better than their male counterparts? Am J Perinatol 2011; 28(3):241-246. doi:10.1055/s-0030-1268239

9. Barker DJ. The fetal and infant origins of adult disease. BMJ 1990 301(6761):1111. doi:10.1136/bmj.301.6761.1111

10. Raju TNK, Pemberton VL, Saigal S, et al. Long-term healthcare outcomes of preterm birth: an executive summary of a conference sponsored by the National Institutes of Health. J Pediatr 2017, 181:309-318.e1. doi:10.1016/j.jpeds.2016.10.015

11. Bayman E, Drake AJ, Piyasena C. Prematurity and programming of cardiovascular disease risk: a future challenge for public health? Arch Dis Child Fetal Neonatal Ed 2014; 99(6):F510-F514. doi:10.1136/archdischild-2014-306742

12. Sullivan MC, Winchester SB, Msall ME. Prematurity and cardiovascular risk at early adulthood. Child Care Health Dev 2019; 45(1):71-78. doi:10.1111/cch.12616

13. Crump C, Sundquist K, Sundquist J, Winkleby MA. Gestational age at birth and mortality in young adulthood. JAMA 2011; 306(11):1233-1240. doi:10.1001/jama.2011.1331

14. Crump C, Winkleby MA, Sundquist J, Sundquist K. Prevalence of survival without major comorbidities among adults born prematurely. JAMA 2019; 322(16):1580-1588. doi:10.1001/jama.2019.15040

15. Bolton CE, Bush A, Hurst JR, Kotecha S, McGarvey L. Lung consequences in adults born prematurely. Thorax 2015; 70(6):574-580. doi:10.1136/thoraxjnl-2014-206590

16. Goss KN, Beshish AG, Barton GP, et al. Early pulmonary vascular disease in young adults born preterm. Am J Respir Crit Care Med 2018; 198(12):1549-1558. doi:10.1164/rccm.201710-20160C

17. Mourani PM, Sontag MK, Younoszai A, et al. Early pulmonary vascular disease in preterm infants at risk for bronchopulmonary dysplasia. Am J Respir Crit Care Med 2015; 191(1):87-95. doi:10.1164/rccm.201409-15940C

18. Naumburg E, Söderström L. Increased risk of pulmonary hypertension following premature birth. BMC Pediatr 2019; 19(1):288 doi:10.1186/s12887-019-1665-6

19. Bertagnolli M, Luu TM, Lewandowski AJ, Leeson P, Nuyt AM.
Preterm birth and hypertension: is there a link? Curr Hypertens Rep 2016; 18(4):28. doi:10.1007/s11906-016-0637-6

20. Luu TM, Rehman Mian MO, Nuyt AM. Long-term impact of preterm birth: neurodevelopmental and physical health outcomes. Clin Perinatol 2017; 44(2):305-314. doi:10.1016/j.clp.2017.01.003

21. Been JV, Lugtenberg MJ, Smets E, et al. Preterm birth and childhood wheezing disorders: a systematic review and meta-analysis. PLoS Med 2014; 11(1):e1001596. doi:10.1371/journal.pmed.1001596

22. Kotecha SJ, Watkins WJ, Lowe J, Granell R, Henderson AJ, Kotecha S. Comparison of the associations of early-life factors on wheezing phenotypes in preterm-born children and term-born children. Am J Epidemiol 2019; 188(3):527-536. doi:10.1093/aje/kwy268

23. Kotecha SJ, Edwards MO, Watkins WJ, et al. Effect of preterm birth on later FEV1; a systematic review and meta-analysis. Thorax 2013; 68(8):760-766. doi:10.1136/thoraxjnl-2012-203079

24. Kotecha SJ, Dunstan FD, Kotecha S. Long term respiratory outcomes of late preterm-born infants. Semin Fetal Neonatal Med 2012; 17(2):77-81. doi:10.1016/j.siny.2012.01.004

25. Näsänen-Gilmore $P$, Sipola-Leppänen M, Tikanmäki M, et al. Lung function in adults born preterm. PLoS One 2018; 13(10):e0205979. doi:10.1371/journal.pone.0205979

26. Stritzke A, Thomas S, Amin H, Fusch C, Lodha A. Renal consequences of preterm birth. Mol Cell Pediatr 2017; 4(1):2. doi:10.1186/s40348-016-0068-0

27. Eriksson JG, Salonen MK, Kajantie E, Osmond C. Prenatal growth and CKD in older adults: longitudinal findings from the Helsinki birth cohort study, 1924-1944. Am J Kidney Dis 2018; 71(1):20-26. doi:10.1053/j.ajkd.2017.06.030

28. Carmody JB, Charlton JR. Short-term gestation, long-term risk: prematurity and chronic kidney disease. Pediatrics 2013; 131(6):11681179. doi:10.1542/peds.2013-0009

29. DeFreitas MJ, Katsoufis CP, Abitbol CL. Cardio-renal consequences of low birth weight and preterm birth. Progress in Pediatric Cardiology 2016; 41:83-88. doi:10.1016/j.ppedcard.2016.01.012

30. Lewandowski AJ, Augustine D, Lamata P, et al. Preterm heart in adult life: cardiovascular magnetic resonance reveals distinct differences in left ventricular mass, geometry, and function. Circulation 2013; 127(2):197-206. doi:10.1161/CIRCULATIONAHA.112.126920

31. Chehade H, Simeoni U, Guignard JP, Boubred F. Preterm birth: long term cardiovascular and renal consequences. Curr Pediatr Rev 2018; 14(4):219-226. doi:10.2174/1573396314666180813121652

32. Benny M, Hernandez DR, Sharma M, et al. Neonatal hyperoxia exposure induces aortic biomechanical alterations and cardiac dysfunction in juvenile rats. Physiol Rep 2020; 8(1):e14334. doi:10.14814/phy2.14334

33. Hovi P, Turanlahti M, Strang-Karlsson S, et al. Intima-media thickness and flow-mediated dilatation in the Helsinki study of very low birth weight adults. Pediatrics 2011; 127(2):e304-e311. doi:10.1542/peds.2010-2199

34. Kowalski RR, Beare R, Doyle LW, Smolich JJ, Cheung MM; Victorian Infant Collaborative Study Group. Elevated blood pressure with reduced left ventricular and aortic dimensions in adolescents born extremely preterm. J Pediatr 2016; 172:75-80.e2. doi:10.1016/j.jpeds.2016.01.020

35. Aye CYL, Lewandowski AJ, Lamata $\mathbf{P}$, et al. Disproportionate cardiac hypertrophy during early postnatal development in infants born preterm. Pediatr Res 2017; 82(1):36-46. doi:10.1038/pr.2017.96

36. Huckstep OJ, Williamson W, Telles F, et al. Physiological stress elicits impaired left ventricular function in preterm-born adults. J Am Coll Cardiol 2018; 71(12):1347-1356. doi:10.1016/j.jacc.2018.01.046

37. de Jong F, Monuteaux MC, van Elburg RM, Gillman MW, Belfort MB. Systematic review and meta-analysis of preterm birth and later systolic blood pressure. Hypertension 2012; 59(2):226-234. doi:10.1161/HYPERTENSIONAHA.111.181784 
38. Cook NR, Cohen J, Hebert PR, Taylor JO, Hennekens CH. Implications of small reductions in diastolic blood pressure for primary prevention. Arch Intern Med 1995; 155(7):701-709. pmid:7695458

39. South AM, Nixon PA, Chappell MC, et al. Association between preterm birth and the renin-angiotensin system in adolescence: influence of sex and obesity. J Hypertens 2018; 36(10):2092-2101. doi:10.1097/HJH.0000000000001801

40. Sehgal A, Krishnamurthy MB, Clark M, Menahem S. ACE inhibition for severe bronchopulmonary dysplasia-an approach based on physiology. Physiol Rep 2018; 6(17):e13821. doi:10.14814/phy2.13821

41. Crump C, Howell EA, Stroustrup A, McLaughlin MA, Sundquist J, Sundquist K. Association of preterm birth with risk of ischemic heart disease in adulthood. JAMA Pediatr 2019; 173(8):736-743. doi:10.1001/jamapediatrics.2019.1327

42. Carr H, Cnattingius S, Granath F, Ludvigsson JF, Edstedt Bonamy AK Preterm birth and risk of heart failure up to early adulthood. J Am Coll Cardiol 2017; 69(21):2634-2642. doi:10.1016/j.jacc.2017.03.572

43. Ream MA, Lehwald L. Neurologic consequences of preterm birth. Curr Neurol Neurosci Rep 2018; 18(8):48. doi:10.1007/s11910-018-0862-2

44. Raju TNK, Buist AS, Blaisdell CJ, Moxey-Mims M, Saigal S. Adults born preterm: a review of general health and system-specific outcomes. Acta Paediatr 2017; 106(9):1409-1437. doi:10.1111/apa.13880

45. Chen LW, Wang ST, Wang LW, et al. Behavioral characteristics of autism spectrum disorder in very preterm birth children. Mol Autism 2019; 10:32. doi:10.1186/s13229-019-0282-4

46. Roggero $\mathbf{P}$, Giannì ML, Garbarino F, Mosca F. Consequences of prematurity on adult morbidities. Eur J Intern Med 2013; 24(7):624-626. doi:10.1016/j.ejim.2013.01.011

47. Bourke J, Wong K, Srinivasjois R, et al. Predicting long-term survival without major disability for infants born preterm. J Pediatr 2019; 215:90-97.e1. doi:10.1016/j.jpeds.2019.07.056

48. Crane JD, Yellin SA, Ong FJ, et al. ELBW survivors in early adulthood have higher hepatic, pancreatic and subcutaneous fat. Sci Rep 2016; 6:31560. doi:10.1038/srep31560

49. Crump C, Winkleby MA, Sundquist K, Sundquist J. Risk of diabetes among young adults born preterm in Sweden. Diabetes Care 2011; 34(5):1109-1113. doi:10.2337/dc10-2108

50. Crump C, Sundquist J, Sundquist K. Preterm birth and risk of type 1 and type 2 diabetes: a national cohort study. Diabetologia 2020; 63(3):508-518. doi:10.1007/s00125-019-05044-z

51. Mathai S, Derraik JG, Cutfield WS, et al. Increased adiposity in adults born preterm and their children. PLoS One 2013; 8(11):e81840. doi:10.1371/journal.pone.0081840

52. Breukhoven PE, Kerkhof GF, Willemsen RH, Hokken-Koelega AC. Fat mass and lipid profile in young adults born preterm. J Clin Endocrinol Metab 2012; 97(4):1294-1302. doi:10.1210/jc.2011-2621

53. Sipola-Leppänen $M$, Vääräsmäki $M$, Tikanmäki $M$, et al. Cardiometabolic risk factors in young adults who were born preterm. Am J
Epidemiol 2015; 181(11):861-873. doi:10.1093/aje/kwu443

54. Sipola-Leppänen M, Kajantie E. Should we assess cardiovascular risk in young adults born preterm? Curr Opin Lipidol 2015; 26(4):282287. doi:10.1097/MOL.0000000000000190

55. Wood CL, Wood AM, Harker C, Embleton ND. Bone mineral density and osteoporosis after preterm birth: the role of early life factors and nutrition. Int J Endocrinol 2013; 2013:902513. doi:10.1155/2013/902513

56. Xie LF, Alos N, Cloutier A, et al. The long-term impact of very preterm birth on adult bone mineral density. Bone Rep 2018; 10:100189. doi:10.1016/j.bonr.2018.100189

57. Crump C, Sundquist J, Winkleby MA, Sundquist K. Gestational age at birth and mortality from infancy into mid-adulthood: a national cohort study. Lancet Child Adolesc Health 2019; 3(6):408-417. doi:10.1016/S2352-4642(19)30108-7

58. Bolton CE, Bush A, Hurst JR, et al. Are early life factors considered when managing respiratory disease? A British Thoracic Society survey of current practice. Thorax 2012; 67(12):1110. doi:10.1136/thoraxjnl-2012-202637

59. Crump C. Birth history is forever: implications for family medicine. J Am Board Fam Med 2015; 28(1):121-123. doi:10.3122/jabfm.2015.01.130317

60. Bonner R, Bountziouka V, Stocks J, et al. Birth data accessibility via primary care health records to classify health status in a multi-ethnic population of children: an observational study. NPJ Prim Care Respir Med 2015; 25:14112. doi:10.1038/npjpcrm.2014.112

61. Kajantie E, Hovi P. Is very preterm birth a risk factor for adult cardiometabolic disease? Semin Fetal Neonatal Med 2014; 19(2):112117. doi:10.1016/j.siny.2013.11.006

62. Matinolli HM, Männistö S, Sipola-Leppänen $M$, et al. Food and nutrient intakes in young adults born preterm. Pediatr Res 2018; 83(3):589-596. doi:10.1038/pr.2017.301

63. Kaseva N, Wehkalampi K, Hemiö K, et al. Diet and nutrient intake in young adults born preterm at very low birth weight. J Pediatr 2013; 163(1):43-48. doi:10.1016/j.jpeds.2012.12.076

64. Tikanmäki M, Tammelin T, Sipola-Leppänen M, et al. Physical fitness in young adults born preterm. Pediatrics 2016; 137(1). doi:10.1542/peds.2015-1289

65. Boivin A, Luo ZC, Audibert F, et al. Risk for preterm and very preterm delivery in women who were born preterm. Obstet Gynecol 2015; 125(5):1177-1184. doi:10.1097/AOG.0000000000000813

66. Grobman WA, Rice MM, Reddy UM, et al. Labor induction versus expectant management in low-risk nulliparous women. N Engl J Med 2018; 379(6):513-523. doi:10.1056/NEJMoa1800566

Address: Cristina I. Pravia, MD, Department of Internal Medicine, University of Miami, 1150 NW 14th Street, Suite 150, Miami, FL 33136; cpravia@med.miami.edu 